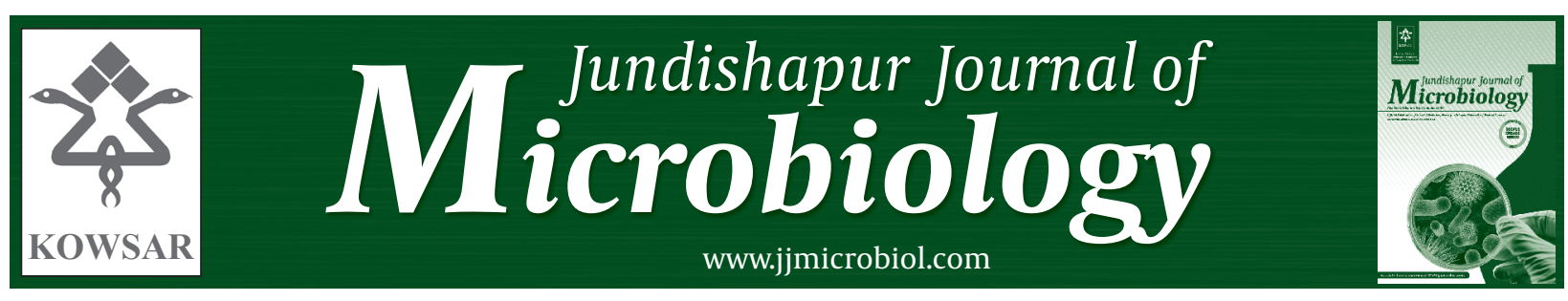

\title{
Protein Profiles of Aspergillus Species Isolated From the Tea Gardens and Factories Air in Northern Iran
}

\author{
Ali Reza Khosravi ${ }^{1^{*}}$, Arash Chaichi Nosrati ${ }^{2}$, Hojjatollah Shokri $^{3}$ \\ ${ }^{1}$ Mycology Research Center, Faculty of Veterinary Medicine, University of Tehran, Tehran, IR Iran \\ ${ }^{2}$ Department of Microbiology \& Cell Biology, Faculty of Basic Sciences, Islamic Azad University, Lahijan Branch, Lahijan, IR Iran \\ ${ }^{3}$ Faculty of Veterinary Medicine, University of Mazandaran, Amol, IR Iran
}

\begin{tabular}{l}
\hline A R T I C L E I N F O \\
\hline Article type: \\
Original Article \\
\hline Article history: \\
Received: 25 Jan 2012 \\
Revised: 11 Apr 2012 \\
Accepted: 16 Apr 2012 \\
\hline
\end{tabular}

Keywords:

Tea

Aspergillus

SDS-PAGE

Protein Band

\begin{abstract}
A B S T R A C T
Background: Spoilage of tea (Camellia sinensis) is often accompanied by contamination and formation of mycotoxins, which are toxic secondary metabolites produced by specific tea-borne fungi.

Objectives: The purposes of this study were to isolate Aspergillus flora in the air from tea gardens and factories in Gilan and Mazandaran provinces, in northern Iran, and to determine their protein patterns.

Materials and Methods: Air samples were collected from 11 tea gardens and 13 tea factories between 2006 and 2008, and cultured in specific fungal media. Mycelial mats and spores of the Aspergillus species were disrupted in liquid nitrogen containing glass beads. The crude extracts were separated from other cell components by centrifugation and sterilized using a filter. The extracts obtained were analysed using sodium dodecyl sulphate-polyacrylamide gel electrophoresis (SDS-PAGE) to separate the fungal antigenic proteins.

Results: A total of 4157 fungal colonies were observed in the tea gardens air and 3950 colonies in the tea factories air. The most dominant and frequently occurring Aspergillus flora were; A. niveus (14.4\%) and A. unguis (12.6\%) in the gardens, and A. melleus (14.3\%) and A. niger (12.3\%) in the factories. The highest number of Aspergillus species collected from the tea gardens and factories were associated with the regions of Lahijan (23.9\%) and Rasht (18.8\%), respectively. The results from the SDS-PAGE method indicated that various Aspergillus species had 55 protein bands, which ranged from 5 to $120 \mathrm{kDa}$. Among these species, A. foetidus had the maximum number of protein bands (22 bands) ranging from 14.4 to $120 \mathrm{kDa}$, while A. unguis contained the minimum protein bands ( 5 bands) ranging from 30 to $120 \mathrm{kDa}$.

Conclusions: The results revealed the presence of a variety of Aspergillus species in tea gardens and factories air, and the presence of a large number of Aspergillus species based upon the protein banding patterns obtained with SDS-PAGE analysis.
\end{abstract}

Published by Kowsar Corp, 2013. cc 3.0.

-Implication for health policy/practice/research/medical education:

Whole-cell protein profiles of Aspergillus species could provide valuable criteria for serological and immunological studies of tea workers exposed to occupational aeroallergens.

- Please cite this paper as:

Khosravi AR, Chaichi Nosrati A, Shokri H. Protein Profiles of Aspergillus Species Isolated From the Tea Gardens and Factories Air in Northern Iran. Jundishapur J Microbiol. 2013;6(1):4-10. DOI: 10.5812/jjm.4250

\footnotetext{
* Corresponding author: Ali Reza Khosravi, Mycology Research Center, Faculty of Veterinary Medicine, P.O.Box:14155-6453, Tehran, IR Iran. Tel:+98-2161117151, Fax: +98-2166933222,E-mail: khosravi@ut.ac.ir
} 


\section{Background}

Aspergillus species are a common group of filamentous fungi, which have universal dissemination and are readily recovered from; soil, decaying vegetation, air and many other environments (1). They produce a large number of conidia (spores), which are turned into aerosols and distributed in the environment. Because of their small size $(<5 \mu \mathrm{m})$ and the aerodynamic properties of the Aspergillus conidia, they can pass through the upper respiratory tract defenses and may reach distal regions of the lungs (2). Aspergillus is a mould that is responsible for a gamut of respiratory diseases ranging from; saprobic colonization to rapidly invasive disseminated disease, especially in individuals with weakened immune systems (3). Aspergillus species are an important source of allergen proteins and have been shown to produce 90 different allergens (4). The clinical spectrum of Aspergillus associated hypersensitivity respiratory disorders includes; asthma, allergic bronchopulmonary aspergillosis (ABPA), allergic Aspergillus sinusitis (AAS) and hypersensitivity pneumonitis. Although A. fumigatus is the most common Aspergillus species known to trigger allergic disorders; A. niger, A. flavus, A. nidulans, A. oryzae and A. terreus have also occasionally been responsible for these conditions (5).

Tea (Camellia sinensis) is one of the most common drinks in the world, enjoyed by many people chiefly in the Far East, Middle East, Europe, Australia and Africa. It has been extensively cultivated in the north of Iran since ancient times and it is known to carry various mycoflora just like any other crop plants, some of which may secrete toxins. Previous studies have shown that the most common fungi isolated from tea gardens are; A. flavus and other species of Aspergillus and Penicillium (6). The processing of black tea involves a series of stages including; withering, rolling, fermenting and firing, before the final product is completed (7). Fungi have been isolated from all stages of tea processing and manufacturing, and recontamination of the final product after firing may also occur during sorting and packaging (8). The possibility that tea may serve as a vehicle for human pathogens has been reported in earlier studies (9). However, no systematic study has been carried out concerning the air spora of tea gardens in Iran, up to now. The high average temperatures and relative humidity of the Gilan and Mazandaran provinces, which are accompanied by poor conditions and prolonged duration of tea storage, promotes the growth of different fungi, in particular Aspergillus species.

\section{Objectives}

The purposes of this study were to isolate Aspergillus flora from tea gardens and factories air in certain regions of Gilan and Mazandaran provinces in northern Iran and to determine the protein patterns of various Aspergillus isolates.

\section{Materials and Methods}

\subsection{Isolation and Identification of Aspergillus Species}

Thirteen regions of Gilan and Mazandaran provinces were selected for data collection; Rasht, Lahijan, Amlash, Rudsar, Foman, Siahkal, Shaft, Langerud, Ramsar, Tonekabon, Chalus, Somesara and Astaneh. The samples were collected using five petri dishes including malt extract agar (MEA) (Merck Co., Darmstadt, Germany), yeast extract agar (YEA) (Merck Co., Darmstadt, Germany), Czapek Dox agar (CDA) (Sigma, St Louis MO, USA), Czapek yeast extract agar (CYEA) (Sigma, St Louis MO, USA) and Sabouraud dextrose agar (SDA) (Merck Co., Darmstadt, Germany) containing chloramphenicol (100 ppm) and tetracycline (50 ppm), from May to October of 2006 to 2008 (10). With the exception of rainy days, samples were exposed to the air for $30 \mathrm{~min}$ at a height of $1.5 \mathrm{~m}$ above the ground. After five days incubation at $25^{\circ} \mathrm{C}$, the colonies were isolated in the various media and observed for the formation of macrocolonies. Micromorphology was observed after microcultivation and Aspergillus strains were identified using the classifications of Klich (11), Kojakivic (12) and Samson (13).

\subsection{Cell Fractionation and Crude Extract Preparation}

Each fungal isolate was cultured in Czapek yeast extract agar at a temperature of $25^{\circ} \mathrm{C}$ for 5 days and then incubated in Czapek Dox broth medium. Incubated broth media were kept at $25^{\circ} \mathrm{C}$ for 7 days on a gyratory shaker (200 rpm). Fungal mycelia and spores were separated from the broth media by centrifugation at $3000 \mathrm{~g}$ for $15 \mathrm{~min}$. The pellets were washed 3 times with $10 \mathrm{mM}$ Phosphate buffered saline (PBS), $\mathrm{pH} 7.5$ by centrifugation at $3000 \mathrm{~g}$ for $15 \mathrm{~min}$. The fungal elements were disrupted in liquid nitrogen containing glass beads (diameter; $1 \mathrm{~mm}$ ) for 25 min. After cell disruption, the crude extracts were separated from other cell components by centrifugation at 3 $000 \mathrm{~g}$ for $15 \mathrm{~min}$. The extracts were sterilized using a filter $\left(0.2 \mu\right.$, Sartorious, USA) and stored at $-20^{\circ} \mathrm{C}$ until required.

\subsection{Determination of Protein}

Protein concentration of the sample was determined after reconstituting in 50 and $100 \mu \mathrm{l}$ of distilled water by the Bradford method (14).

\subsection{Sodium Dodecyl Sulphate-Polyacrylamide Gel Elec- trophoresis (SDS-PAGE)}

SDS-PAGE was performed using the Laemmli method (15). The fungal extracts were dissolved in a sample buffer (Novex, San Diego, CA, USA) and boiled for $5 \mathrm{~min}$. Aliquots of the sample (volum $=10 \mu \mathrm{l}$, which equals $60 \mu \mathrm{g}$ of the protein) and standard markers ( $3 \pm 185 \mathrm{kDa}$ ) (Novex, San Diego, CA, USA) were applied to a Novex precast NuBisTris gel $(4 \pm 12 \%)$ for the separation of fungal antigenic proteins. Electrophoresis was performed with a Novex X 
cell II mini-cell for $40 \mathrm{~min}$ at a constant voltage of 200 watt. The gel was fixed and stained with $0.1 \%$ Coomassie Brilliant Blue.

\subsection{Statistical Analysis}

The data analysis was undertaken with a SPSS (version no.12) program using the Student's t-test statistical methu od for analysis of significance. A $p$ value less than 0.05 was regarded as significant.

\section{Results}

The results of the aeromycoflora study showed that the air of tea gardens and factories is never free of fungal spores. The sum of 4157 (51.3\%) and 3950 (48.7\%) Aspergillus colonies were obtained from the tea gardens and factories of Gilan and Mazandaran provinces, respectively. Of those colonies, 16 species were identified from gardens and 14 species from factories. As illustrated in Table 1, A. niveus (14.4\%), A. unguis (12.6\%) and A. alliaceus (9.7\%) were the most frequent Aspergillus species isolated from the tea gardens, while A. melleus (14.3\%), A. niger (12.3\%) and A. flavus (11.6\%) were found to be the most predominant Aspergillus species obtained from the tea factories. Our results showed that toxigenic species such as; A. flavus and A. parasiticus, were higher in number than the other Aspergillus species, especially inside the tea factories. Table 1 shows the population of different Aspergillus species from 11 tea gardens and 13 tea factories in a number of Iranian regions. The highest number of Aspergillus species that were obtained from tea gardens were associated with the regions of Lahijan (23.9\%), followed by Rudsar (14.7\%) and Rasht (14.3\%). The tea factories with the highest level of Aspergillus species contamination were found in Rasht (18.8\%), followed by Lahijan (16.4\%) and Rudsar (11.8\%).

In the present study, results from the SDS-PAGE method indicated that extracts obtained from various Aspergillus species had 55 protein bands, which ranged from 5 to $120 \mathrm{kDa}$ (Figure 1 and Table 2). Most bands were concentrated between 14.4 and $55 \mathrm{kDa}$ in all of the species. Among these species, A. foetidus had the maximum number of protein bands (22 bands) ranging from 14.4 to $120 \mathrm{kDa}$ and $A$. unguis had the minimum protein bands ( 5 bands) ranging from 30 to $120 \mathrm{kDa}$. Among the different bands, protein bands with a molecular weight of $120 \mathrm{kDa}$ were present in all species of Aspergillus except for; A. fumigatus, A. parasiticus, A. carbonarius, A. ochraceus and A. ostianus. A band with a weight of 116 $\mathrm{kDa}$ was observed in all of the 18 species of Aspergillus except for; A. wentii, A. parasiticus and A. awamori. Thus, common protein bands including 120 and $116 \mathrm{kDa}$ were detected with a frequency of $72.3 \%$ and $83.4 \%$ in different species of Aspergillus, respectively. Regarding the results of common protein bands and according to the statistical analysis, no meaningful relationship was observed among the protein bands obtained from different Aspergillus species in this current study.

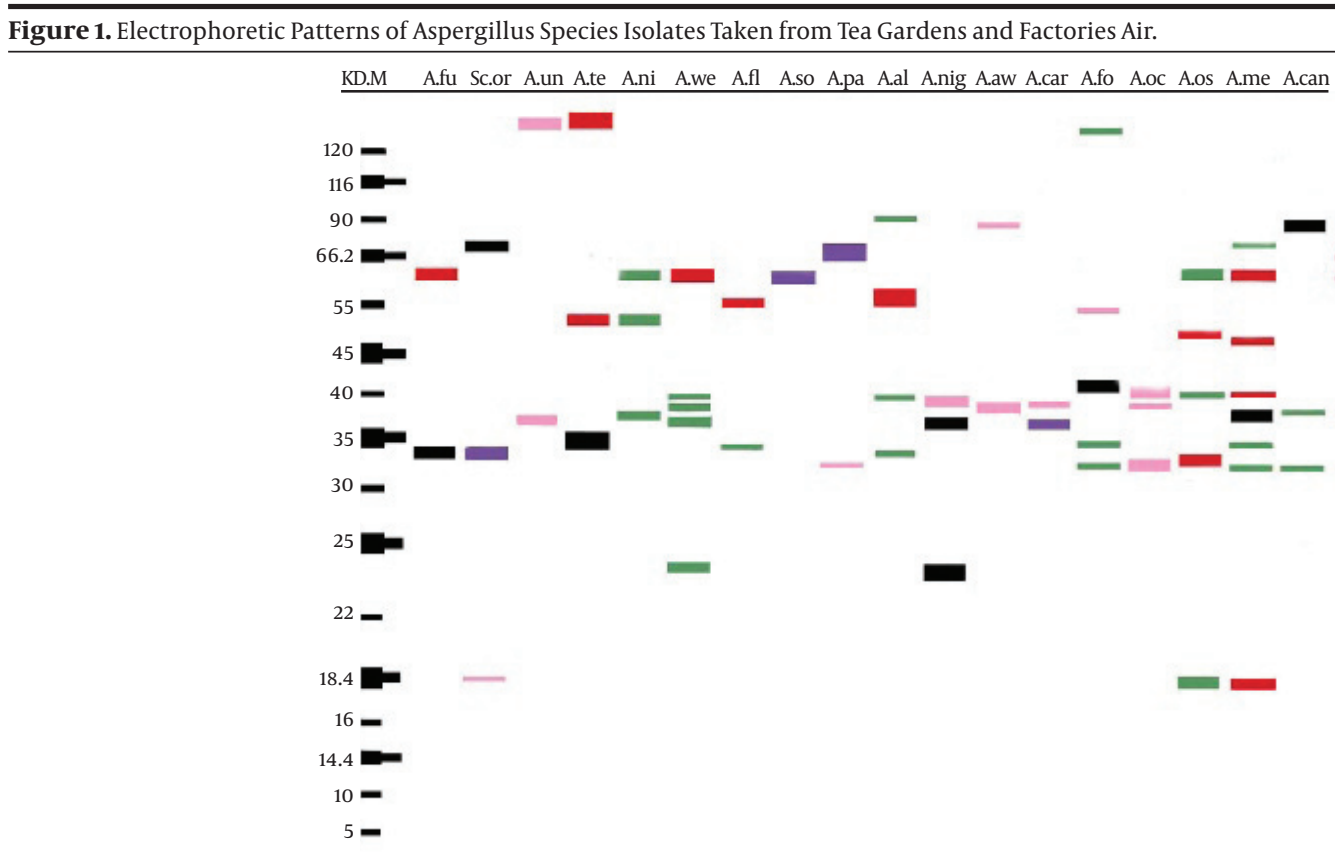

Abbreviations: M, Marker; A.fu, Aspergillus fumigatus; Sc.or, Sclerocleista ornata; A.un, Aspergillus unguis; A.te, Aspergillus terreus; A.ni, Aspergillus niveus A.we, Aspergillus wentii; A.fl, Aspergillus flavus; A.so, Aspergillus sojae; A.pa, Aspergillus parasiticus; A.al, Aspergillus alliaceus; A.nig, Aspergillus niger; A.aw, Aspergillus awamori; A.car, Aspergillus carbonarius; A.fo, Aspergillus foetidus; A.oc, Aspergillus ochraceus; A.os, Aspergillus ostianus; A.me, Aspergillus melleus; A.can, Aspergillus candidus 


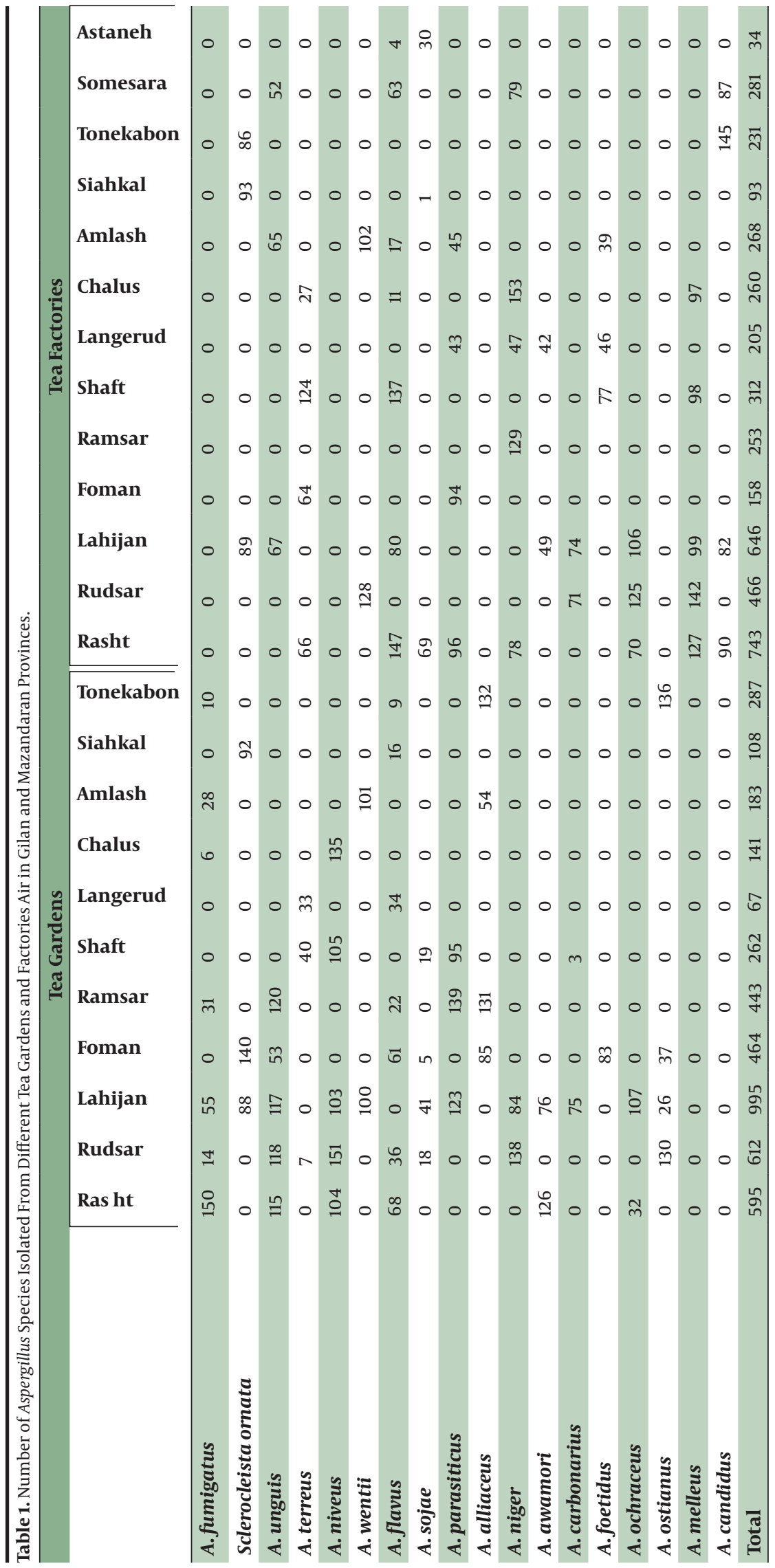




\begin{tabular}{|c|c|c|}
\hline & Protein bands, kDa & Total (bands) \\
\hline A.fumigatus & $116,66.2,45,35,30,16.4$ & 6 \\
\hline Sclerocleista ornata & $120,116,110,68,60,50,45,35,26,18.4,16$ & 11 \\
\hline A.unguis & $120,116,55,37,30$ & 5 \\
\hline A. terreus & $120,116,66.2,60,55,45,35,30,27$ & 9 \\
\hline A. niveus & $120,116,70,66,55,38$ & 6 \\
\hline A. wentii & $120,66.2,47,45,40,37,35,28,25,24,14.4$ & 11 \\
\hline A.flavus & $120,116,90,66.2,59,55,45,44,40,35,32,27,26,22,18.4,17.6,14.4$ & 17 \\
\hline A. sojae & $120,116,70,66.2,40,30,28,14.4$ & 8 \\
\hline A. parasiticus & $116,66.2,70,55,50,45,42,37,33,25,17,15,14.4,10,5$ & 15 \\
\hline A. alliaceus & $120,116,92,57,47,40,35,34,30,14.4$ & 10 \\
\hline A. niger & $120,116,75,57,45,40,37,35,32,25,24,14.4$ & 12 \\
\hline A. awamori & $120,90,45,40,25,24,20,18.4$ & 8 \\
\hline A. carbonarius & $116,90,66.2,55,54,45,43,39,37,34,33,30,27,25,23,18.4,17.4,14.4,10$ & 19 \\
\hline A. foetidus & $120,116,95,90,66.2,55,45,44,43,42,41,37,35,33,30,25,24,20,10,18.4,17.4,14.4$ & 22 \\
\hline A. ochraceus & $116,66.2,47,45,44,41,40,39,34,30,29,24,20,19.4,18.4,17.4,15.4,14.4,10$ & 19 \\
\hline A. ostianus & $116,66.2,55,44,43,41,37,32,30,27,18.4,16.4,10$ & 13 \\
\hline A. melleus & $120,116.2,90,80,70,66.2,53,46,42,40,38,35,33,30,20.4,18.4,17,14.4$ & 18 \\
\hline A. candidus & $120,116,90,55,45,40,38,33,26$ & 9 \\
\hline
\end{tabular}

\section{Discussion}

Aspergillus species are well-known as causative agents of opportunistic infections in humans. Aspergillus antigens can also induce the development of hypersensitive respiratory processes (4), although their frequency, epidemiological characteristics and clinical relevance are still unknown, this is partly due to insufficient knowledge of these antigens.

In this present study, a total of 4157 and 3950 Aspergillus colonies were obtained from tea gardens and factories, respectively, from different regions of Gilan and Mazandaran provinces. The most frequent Aspergillus species isolated from the tea gardens and factories were found to be A. niveus (14.4\%) and A. melleus (14.3\%), respectively. In a study conducted by Sharma (16), A. fumigatus had the highest percentage contribution (18\%), followed by A. flavus (12.6\%), A. niger (9.2\%), A. ochraceus (2.3\%) and A. japonica $(2.3 \%)$ in the air of the Darjeeling tea garden, India. Hasan and Abdel-Sater (17) indicated that Aspergillus was the most predominant genus encountered in all of the black tea samples comprising $92.3 \%$ of the total fungi. From the Aspergillus genus, 11 species and 1 variety were identified of which; A. flavus, A. fumigatus, A. niger and A. terreus were the most common. Other studies have reported Aspergillus species to be the most dominant fungi in all of the tea brands $(18,19)$.

A few of the fungal isolates are known to be mycotoxin producers, such as; A. flavus and A. parasiticus (20). In this study, the occurrence of these toxigenic fungi was high in comparison to that of the other Aspergillus species, especially in the tea factories. Our results are not in agreement with Dutta et al. (21), who reported a low frequency of aflatoxigenic Aspergillus species in the air of a tea fac- tory in the Cachar district, Assam, India. Although not all A. flavus strains are aflatoxigenic, a high incidence of aflatoxigenic strains (50-100\%) are usually found among A. flavus isolates (22). Keeping the above view in mind, information regarding the probable mycotoxin producing air mycoflora in relation to the tea garden and factory and their mycotoxin producing ability in tea, it should be given due importance. Mycotoxins are secondary fungal metabolites with well-known health effects including; carcinogenesis, immunosuppression and cytotoxicity on alveolar macrophages (23). They are products that become poisonous and elicit a toxic response known as mycotoxicoses when food or feed containing them is eaten by humans or animals (24). There is evidence that aflatoxins can become air-borne and circumstantial evidence suggests that aflatoxins may also occur in the air. In fact, aflatoxins have been found in; spores, fungal hyphae and substrate materials, all of which could be released into the air when toxigenic fungi sporulate on indoor building materials. Their rate of inhalation can be up to 40 times greater than by ingestion (25). This raises the possibility of potentially hazardous exposures to the inhabitants of contaminated spaces.

In the present study, the highest number of Aspergillus species obtained from the tea gardens and factories were associated with the regions of Lahijan (23.9\%) and Rasht (18.8\%), respectively. Aerosolized Aspergillus spores are found nearly everywhere so we are routinely and almost constantly exposed to them. They can cause human and animal diseases through the production of mycotoxins, by the induction of allergenic responses and through localized or systemic infections (26). Occupational mycoses are forms of extrinsic allergic alveolitis. They are all 
inflammatory reactions caused by breathing in high concentrations of fungal spores and other antigenic organic matter. Farmer's lung, one of the best known of these, is an occupational mycosis correlated with inhalation of high concentrations of Aspergillus spores from contaminated agricultural products (27).

The results from the SDS-PAGE analysis indicated that extracts obtained from various Aspergillus species contained 55 protein bands with molecular weights between 5 and $120 \mathrm{kDa}$. The highest protein bands were associated with A. foetidus (22 bands) in a range from 14.4 to $120 \mathrm{kDa}$, while the lowest ones were detected in A. unguis ( 5 bands) in a range from 30 to $120 \mathrm{kDa}$. Protein bands of 120 and 116 $\mathrm{kDa}$ had $72.3 \%$ and $83.4 \%$ frequencies in different species of Aspergillus, respectively. Our results are in close agreement with previous investigations. In a study by Saeednejad et al. (28), 69 protein bands with molecular weights between 11.5 and $178 \mathrm{kDa}$ were identified. Among these, protein bands with molecular weights of 15, 23.5, 27, 33.5 and $61 \mathrm{kDa}$ were found in two species, A. fumigatus and $A$. flavus, protein bands $28.5,40$ and $47 \mathrm{kDa}$ were found in two species of A. flavus and A. niger, and a band with 120 $\mathrm{kDa}$ was found in A. fumigatus and A. niger. Identification of a protein in a complex antigenic extract on the sole basis of its molecular weight is a difficult process and sometimes the same antigen may have small differences in molecular weight in different studies. In addition, the differences observed in molecular weight may be related to differences in the calculation of the molecular weight or to the presence of several antigens with the same molecular weight, the species used as the source of antigenic proteins and sometimes even the methods of detection.

In conclusion, A. niveus and A. melleus were the predominant Aspergillus species found in tea gardens and factories air, respectively. In SDS-PAGE, 22 and 5 protein bands were detected in A. foetidus and A. unguis, respectively. The wholecell proteins profile obtained by the SDS-PAGE analysis can provide valuable criteria for serological and immunological studies of tea workers exposed to occupational aeroallergens. Also, the results obtained do not support the concept that such protein patterns can be used in the identification of species, however, it suggests that this technique might be of value in assessing the degree of similarity among species of the same genus or of closely related genera.

\section{Acknowledgements}

None declared.

\section{Financial Disclosure}

None declared.

\section{Funding/Support}

Funding for this work was provided by the Research Council of the University of Tehran, Iran (Grant\#3208).

\section{Authors' Contribution}

None declared.

\section{References}

1. Larone DH. Medically important fungi: a guide to identification. Amer Society for Microbiology; 2002.

2. Kanaani H, Hargreaves M, Smith J, Ristovski Z, Agranovski V, Morawska L. Performance of UVAPS with respect to detection of airborne fungi. J Aerosol Sci. 2008;39(2):175-89.

3. Ho PL, Yuen KY. Aspergillosis in bone marrow transplant recipients. Crit Rev Oncol Hematol. 2000;34(1):55-69.

4. Bowyer P, Denning DW. Genomic analysis of allergen genes in Aspergillus spp: the relevance of genomics to everyday research. Med Mycol. 2007;45(1):17-26.

5. Shah A. Aspergillus-associated hypersensitivity respiratory disorders. Indian J Chest Dis Allied Sci. 2008;50(1):117-28.

6. George K, Phukan I, Goswarni M, Cas A, editors. Microorganisms in made tea: Change in chemical components and quality; 1994.

7. Kochhar S. Tropical crops: a textbook of economic botany. Macmillan Publ.; 1986.

8. Kotzè TECJM. Microbiological aspects of tea manufacture in South Africa. Acta Horticulturae. 1990;275:6gi.

9. Ekanayaka A, Kariyawasarn WS, Kanthasarny P. A study on the microorganisms and their activities associated with storage. Sri Lanka J Tea Sci. 1987;56(1):12-21.

10. Osmani SA, Goldman GH. The Aspergilli: genomics, medical aspects, biotechnology, and research methods. CRC; 2008.

11. Klich MA, Center USARSSRR. Identification of common Aspergillus species. Centraalbureau voor Schimmelcultures Utrecht; 2002.

12. Kozakiewicz Z. Aspergillus species on stored products. CAB International; 1989.

13. Samson RA, Pitt JI. Integration of modern taxonomic methods for Penicillium and Aspergillus classification. CRC; 2000.

14. Bradford MM. A rapid and sensitive method for the quantitation of microgram quantities of protein utilizing the principle of protein-dye binding. Anal Biochem. 1976;72:248-54.

15. Laemmli UK. Cleavage of structural proteins during the assembly of the head of bacteriophage T4. Nature. 1970;227(5259):6805 .

16. Sharma K. Comparative Study of Aeromycoflora in Relation to Soil Myco nol. 2011;3(5).

Recent Res Sci Tech-

7. Hasan HAH, Abdel-Sater MA. Studies on mycoflora and aflatoxin in regular and decaffeinated black tea.J Islamic Acad Sci. 1993;6(2):124-30.

18. Elshafie AE, Al-Lawatia T, Al-Bahry S. Fungi associated with black tea and tea quality in the Sultanate of Oman. Mycopathologia. 1999;145(2):89-93.

19. Shuchi S, Anchal S, Shivesh S, Vivek K, Deep SK, Piyush P. Studies on rhizospheric mycoflora of tea (Camellia sinensis): in vitro antagonism with dominant bacteria. Chin J Appl Environ Biol. 2007;13(3):357-60.

20. Hayes LC, Plapp FV, Tilzer LL, Chiga M. Characterization of monosomes produced by aflatoxin B1. Chem Biol Interact. 1975;10(5):3437.

21. Dutta S, Dutta B, Nath P. Some Observations on the Aeromycoflora of Tea Factory in Cachar, District, Assam. Assam Uni J Sci Technol. 2010;4(1):13-9.

22. Heperkan D, Aran N, Ayfer M. Mycoflora and aflatoxin contamination in shelled pistachio nuts.J Sci Food Agric. 1994;66(3):273-8.

23. Betina V. Mycotoxins. Chemical, biological and environmental aspects. Elsevier; 1989.

24. Peraica M, Radic B, Lucic A, Pavlovic M. Toxic effects of mycotoxins in humans. Bulletin of the World Health Organization. 1999;77(9):754-66.

25. Craesia DA, Thurman JD, Jones LJ. Acute inhalation toxicity of T-2 mycotoxin in mice. Fund Appl Toxicol.1987;8(2):230-5.

26. Bush RK, Portnoy JM, Saxon A, Terr AI, Wood RA. The medical ef- 
fects of mold exposure. J Allergy Clin Immunol. 2006;117(2):326-33.

27. Salvaggio JE. Extrinsic allergic alveolitis (hypersensitivity pneumonitis): past, present and future. Clin Exp Allergy. 1997;27 Suppl 1:18-25.
28. Saeednejad L, Sabokbar A, Khosravi A, Bayat M, Bakhtiari A. Determining Protein Patterns for Three Fungus Species Aspergillus fumigatus, Asp .Flavus and Asp. Niger, Obtained from Outdoor Air in Iran. Global Veterinaria. 2010;4(2):130-4. 